\title{
Faktor-Faktor yang Berhubungan dengan Putus Berobat Pada Penderita TB Paru BTA Positif (+ ) di Wilayah Kerja Puskesmas Harapan Raya
}

\section{The Factors That Deals In A Medical Treatment By Those With Pulmonary Tuberculosis BTA + In The Work Area Puskesmas Harapan Raya}

\author{
Khamidah, Herlina Susmaneli
}

\section{Prodi IKM STIKes Hang Tuah Pekanbaru}

\begin{abstract}
ABSTRAK
Putus berobat adalah pasien yang tidak berobat 2 bulan berturut-turut atau lebih sebelum masa pengobatannya selesai. Angka putus berobat di Puskesmas Harapan Raya diperkirakan mencapai 40\%. Akibat putus berobat adalah pasien bisa kebal terhadap obat (MDR=Multi Drugs Resisten). Penelitian ini dilakukan pada bulan Mei sampai Juni 2015. Penelitian ini bertujuan untuk melihat apakah umur, jenis kelamin, tidak ada PMO dan kunjungan keyankes merupakan faktor -faktor yang berhubungan dengan putus berobat pada penderita TB Paru BTA +. Jenis penelitian ini bersifat kuantitatif observasional dengan desain kasus kontrol dimana sampel diambil dengan cara menghitung mundur jumlah kasus dan kontrol berdasarkan data TB 01 dengan jumlah sampel 120 sampel terdiri dari 60 sampel kasus dan 60 sampel kontrol yang dilaksanakan di wilayah kerja Puskesmas Harapan Raya. Alat ukur yang digunakan adalah Data TB 01. Analisis data untuk uji bivariat dengan uji chisquare. Hasil penelitian yaitu ada hubungan antara putus berobat dengan umur diperoleh Pvalue 0,011 (OR= $3,500)$, tidak ada hubungan putus berobat dengan jenis kelamin diperoleh Pvalue $0,180(\mathrm{OR}=1,807)$, ada hubungan putus berobat dengan tidak ada PMO diperoleh Pvalue $0,004(\mathrm{OR}=3,778)$ dan ada hubungan putus berobat dengan kunjungan keyankes diperoleh Pvalue 0,001 $(\mathrm{OR}=6,057)$. Sebagai kesimpulan dari penelitian ini dapat dikatakan bahwa antara umur, ada tidaknya PMO dan kunjungan keyankes merupakan faktor resiko putus berobat dan dari hasil uji chi-square jenis kelamin merupakan bukan faktor resiko terjadinya putus berobat pada penderita TB Paru BTA +. Saran bagi petugas kesehatan Puskesmas agar lebih menekankan bagi penderita TB Paru yang berusia produktif agar melakukan pengobatan hingga tuntas, memiliki PMO, memberi dorongan agar pengobatannya termotivasi dari diri sendiri.
\end{abstract}

Kata Kunci: Jenis kelamin, kunjungan kepelayanan kesehatan, putus berobat, tidak ada PMO, umur

\section{ABSTRACT}

Dropped out of medical treatment is patients who are not medical treatment 2 consecutive months or more before the treatment done.The drop out rate treatment at puskesmas hope raya estimated to reach $40 \%$. This report is written in may till june 2015 . This study attempts to see if the age, sex, there is no visit pmo and the visit to the health service a factor, factors that deals in a medical treatment by those with pulmonary tuberculosis smear + . The kind of research is aimed to quantitative control observational with the design cases where taken by means of sample counting down the number of cases and control based on the data tb 01 in sample the total sample 120 consisting of 60 sample cases and 60 sample control exercised raya puskesmas hope in the work area.A measuring instrument used is the data on tb 01 . Of the data analysis to assay bivariat chi-square by test. The result of chisquare test done which is the relation of breaking up of medical treatment by age obtained pvalue 0,011 (or = $3.500)$, the relation of breaking up of medical treatment to the sex obtained pvalue 0,180 ( or = 1,807), the relation of dropping out of treatment with no pmo obtained pvalue 0,004 ( or $=3,778$ relationship and breaking up of medical treatment with a visit to health services obtained pvalue 0,001 ( or =6,057). As the conclusion of this research can be said that between the ages, pmo and a visit to the whereabouts of health services is breaking up of medical treatment and risk factors chi-square test results of the sexes is not a factor of the risk of dropping out of medical treatment in people with pulmonary tuberculosis smear + . Advice for health workers to better emphasize health center for patients with pulmunory TB productive age in order to carry out the treatment to its conclusion, heving a PMO, give impetus that motivated treatment of the self.

Keywords: Drop out of treatment was age, sexes, no pmo, the visit to the health service

\footnotetext{
${ }^{1}$ Alamat Korespondensi: Herlina Susmaneli, Email: neli_herlina@yahoo.co.id
} 


\section{PENDAHULUAN}

Putus berobat bagi penderita TB adalah pasien yang tidak berobat 2 bulan berturut-turut atau lebih sebelum masa pengobatannya selesai (Depkes RI, 2011). Akibat putus berobat adalah pasien bisa kebal terhadap obat $(\mathrm{MDR}=$ Multi Drugs Resisten),sehingga bakteri Mycobacterium yang menyebabkan tuberkulosis akan kebal terhadap obat dikatakan sebagai bakteri pembunuh massal. WHO memperkirakan bakteri ini telah membunuh sekitar 2 juta jiwa setiap tahunnya. Antara tahun 2002-2020 diperkirakan sekitar 1 miliar manusia akan terinfeksi. Dengan kata lain pertambahan jumlah infeksi lebih dari 56 juta jiwa setiap tahunnya. Jika dilakukan perhitungan, pertambahan jumlah pasien TBC akan bertambah sekitar 2,8-5,6 juta jiwa setiap tahun, dan 1,1-2,2 juta jiwa meninggal setiap tahun karena TBC. Depkes RI memperkirakan bahwa setiap tahunnya Indonesia tercatat 429.730 kasus baru TB dengan angka kematian 62.246 (Depkes RI 2011).

Di Provinsi Riau diperkirakan angka penemuan kasus $(\mathrm{CDR}=$ Case Detection Rate) untuk TB Paru pada tahun 2015 mencapai 10.105 kasus. Sementara itu menurut data dari Dinas Kesehatan Provinsi Riau angka putus berobat TB Paru di Riau mengalami penurunan namun untuk Kota Pekanbaru angka putus berobat TB Paru mengalami peningkatan dari tahun 2011 sebanyak 9,6\% , tahun 2012 sebanyak 14,7\% dan dari tahun 2013 sebanyak 14,5\%. Untuk puskesmas di Kota Pekanbaru, Puskesmas Harapan Raya merupakan puskesmas dengan angka kasus TB Paru terbanyak yaitu 150 kasus dengan angka putus berobat pasien TB paru sebanyak 61 kasus (40\%). Tingginya angka kasus putus berobat di Puskesmas Harapan Raya dapat dipengaruhi oleh beberapa faktor yaitu umur, jenis kelamin, tidak ada PMO dan kunjungan kepelayanan kesehatan.

\section{METODE}

Jenis penelitian yang digunakan adalah studi kasus kontrol (case control study),kasus yaitu seluruh penderita TB Paru BTA (+) yang putus berobat di wilayah kerja Puskesmas Harapan Raya dan kontrol yaitu seluruh penderita TB Paru BTA (+) yang tidak putus berobat dengan hasil akhir pengobatan dinyatakan sembuh.

Prosedur pengambilan sampel dilakukan pada bulan Mei 2014, mundur kebelakang sampai tahun 2010. Kasus dan kontrol didapatkan dari catatan TB 01, dengan jumlah sampel kasus 60 orang dan sampel kontrol 60 orang. Jenis data yang dikumpulkan adalah data skunder yaitu data yang diperoleh melalui penelusuran dokumen dari hasil akhir pengobatan putus berobat dan yang dinyatakan sembuh dari kolom rumput pada data TB 01 di Puskesmas Harapan Raya Pekanbaru. Data skunder tersebut terdiri dari 4 variabel yang diteliti yaitu umur, jenis kelamin, tidak ada PMO dan kunjungan kepelayanan kesehatan.

Pengolahan data dilakukan dalam tahaptahap editing, coding, processing, dan cleaning. Analisis data dilakukan dengan menggunakan analisisi univariat dan analisis bivariat dengan uji chi square.

\section{HASIL}

\section{Analisis Univariat}

Pada analisis univariat didapat hasil mayoritas penderita TB Paru BTA + yang beresiko putus berobat yaitu umur sebanyak 52 orang $(86,7 \%)$, tidak ada PMO yaitu sebanyak 19 orang $(31,7 \%)$, kunjungan ke yankes yaitu sebanyak 28 orang $(46,7 \%)$ dan jenis kelamin yaitu sebanyak 43 orang $(71,7 \%)$.

Tabel 1

Analisis Univariat

\begin{tabular}{|c|c|c|c|c|c|}
\hline \multirow[t]{2}{*}{$\begin{array}{l}\text { Kelompok Umur } \\
\text { (Tahun) }\end{array}$} & \multicolumn{2}{|c|}{ Putus berobat } & \multicolumn{2}{|c|}{$\begin{array}{c}\text { Tidak } \\
\text { putus } \\
\text { berobat }\end{array}$} & \multirow[t]{2}{*}{ Jumlah } \\
\hline & $\mathbf{N}$ & $\%$ & $\mathrm{n}$ & $\%$ & \\
\hline Produktif & 52 & 86,7 & 39 & 65,0 & 91 \\
\hline Tidak Produktif & 8 & 13,3 & 21 & 35,0 & 29 \\
\hline Total & 60 & 100 & 60 & 100 & 120 \\
\hline \multicolumn{6}{|l|}{ Jenis Kelamin } \\
\hline Laki-laki & 43 & 71,7 & 35 & 58,3 & 78 \\
\hline Perempuan & 17 & 28,3 & 25 & 41,7 & 42 \\
\hline Total & 60 & 100 & 60 & 100 & 120 \\
\hline \multicolumn{6}{|l|}{ Tidak Ada PMO } \\
\hline Tidak Ada PMO & 19 & 31,7 & 7 & 11,7 & 26 \\
\hline Ada PMO & 41 & 68,3 & 53 & 88,3 & 94 \\
\hline Total & 60 & 100 & 60 & 100 & 120 \\
\hline \multicolumn{6}{|l|}{$\begin{array}{c}\text { Kunjungan } \\
\text { Keyankes }\end{array}$} \\
\hline Rujukan UPK & 28 & 46,7 & 9 & 15,0 & 37 \\
\hline Inisiatif Sendiri & 32 & 53,3 & 51 & 85,0 & 83 \\
\hline Total & 60 & 100 & 60 & 100 & 120 \\
\hline
\end{tabular}

\section{Analisis Bivariat}

Dari hasil analisis bivariat didapatkan 3 variabel yang berhubungan secara signifikam yaitu umur (pvalue $=0,011$ ), tidak ada PMO (pvalue $=0,004), \quad$ kunjungan keyankes (pvalue $=0,001$ ) dan variabel yag tidak berhubungan yaitu jenis kelamin (pvalue $=0,180$ ). 
Tabel 2

Hasil Analisis Bivariat

\begin{tabular}{|c|c|c|c|c|c|c|c|c|}
\hline \multirow[t]{2}{*}{ Kelompok Umur (Tahun) } & \multicolumn{2}{|c|}{ Putus berobat } & \multicolumn{2}{|c|}{$\begin{array}{c}\text { Tidak Putus } \\
\text { Berobat }\end{array}$} & \multicolumn{2}{|c|}{ Total } & \multirow[t]{2}{*}{ P Value } & \multirow[t]{2}{*}{ OR 95\% CI } \\
\hline & $\mathbf{n}$ & $\%$ & $\mathbf{n}$ & $\%$ & $\mathbf{n}$ & $\%$ & & \\
\hline Produktif & 52 & 86,7 & 39 & 65,0 & 91 & 75,8 & 0,011 & $3,500(1,403-8,730)$ \\
\hline Tidak Produktif & 8 & 13,3 & 21 & 35,0 & 29 & 24,2 & & \\
\hline Total & 60 & 100 & 60 & 100 & 120 & 100 & & \\
\hline \multicolumn{9}{|l|}{ Jenis Kelamin } \\
\hline Laki-laki & 43 & 71,7 & 35 & 58,3 & 78 & 65,0 & 0,180 & $1,807(0,844-3,866)$ \\
\hline Perempuan & 17 & 28,3 & 25 & 41,7 & 42 & 35,0 & & \\
\hline Total & 60 & 100 & 60 & 100 & 120 & 100 & & \\
\hline \multicolumn{9}{|l|}{ Tidak Ada PMO } \\
\hline Tidak Ada & 24 & 40,0 & 9 & 15,0 & 33 & 27,5 & \multirow{2}{*}{0,004} & \multirow{2}{*}{$3,778(1,572-9,079)$} \\
\hline Total & 60 & 100 & 60 & 100 & 120 & 100 & & \\
\hline \multicolumn{9}{|l|}{ Kunjungan Keyankes } \\
\hline Inisiatif sendiri & 31 & 51,7 & 9 & 15,0 & 40 & 33,3 & \multirow{3}{*}{0,001} & \multirow{3}{*}{$6,057(2,535-14,472$} \\
\hline Rujukan UPK & 29 & 48,3 & 51 & 85,0 & 80 & 66,7 & & \\
\hline Total & 60 & 100 & 60 & 100 & 120 & 100 & & \\
\hline
\end{tabular}

\section{PEMBAHASAN}

\section{Umur}

Ada hubungan yang bermakna antara umur dengan putus berobat penderita TB Paru, dan umur penderita TB Paru yang produktif berpeluang sebesar 3,500 kali beresiko terjadinya putus berobat dibanding dengan umur yang tidak produktif.

Umur atau usia adalah satuan waktu yang mengukur keberadaan suatu benda atau makhluk, baik yang hidup maupun yang mati. Data Depkes RI, tahun 2002 pada pedoman penanggulangan Tuberkulosis yang menyatakan bahwa penderita TBC terbanyak pada usia produktif (15-55 tahun). Berdasarkan teori pada usia produktif proporsi yang bekerja lebih banyak (74\%) sehingga masih banyak $(34,4 \%)$ yang tidak patuh dalam berobat TB sampai tuntas sehingga ketidaksembuhan pasien TBC dapat menjadi faktor penular dilingkungan pasien.

Hal ini sesuai dengan penelitian yang dilakukan Widayati dkk (2013) bahwa sebagian besar responden TB Paru yang Default usia produktif yaitu $15-55$ tahun sebanyak $63,6 \%$ dan tidak produktif $>55$ tahun sebanyak 12 orang (36,4\%). Menurut penelitian Ramadani (2012), Pada subyek penelitiannya berdasarkan kelompok umur lebih dari $70 \%$ berusia produktif antara umur 20 sampai dengan 50 tahun.

Penderita TB Paru yang dikategorikan usia produktif umumnya aktifitas cukup tinggi dalam sehari-hari sehingga kadang- kadang terlupakan untuk datang berobat dan minum obat secara teratur. Sedangkan usia tidak produktif kebanyakan orang tua yang tidak banyak kegiatan diluar rumah sehingga lebih teratur untuk berobat. Maka Umur sangat berpengaruh terhadap kepatuhan penderita TB dalam menjalani pengobatan.

\section{Jenis Kelamin}

Tidak terdapat hubungan yang bermakna antara responden yang berjenis kelamin dengan putus berobat penderita TB Paru, dan penderita TB Paru jenis kelamin laki-laki dan perempuan memiliki resiko terjadinya putus berobat. Berdasarkan hasil penelitian didapat bahwa mayoritas penderita TB Paru adalah berjenis kelamin laki-laki sebanyak 78 orang $(65,0 \%)$.

Berdasarkan hasil penelitian yang dilakukan Erawatiningsih dkk (2009) yang dilakukan di Dinas Kesehatan Kabupaten Dompu Nusa Tenggara Barat, bahwa tidak ada pengaruh yang signifikan jenis kelamin terhadap ketidakpatuhan berobat pada penderita TB paru dengan nilai koefisien korelasi parsial sebesar 1,000 dengan $\mathrm{p}=$ 0,323 , karena $p>0,05$.

Penelitian ini sejalan dengan penelitian Priska Kondoy dkk (2012) yang dilakukan di lima puskesmas dikota Manado, bahwa jenis kelamin tidak mempunyai hubungan dengan tingkat kepatuhan berobat pasien TB Paru didapat hasil $\mathrm{P}=0,549$. Selain itu penelitian lain juga diungkapkan oleh Kulkarni dari India bahwa tidak ada hubungan jenis kelamin dengan kepatuhan 
berobat pasien TB Paru dan jumlah penderita TB Paru lebih banyak laki-laki 108 responden $(63,2 \%)$ dibandingkan perempuan 63 responden $(36,8 \%)$, hal ini serupa dengan penelitian Pant yang menyatakan bahwa $70 \%$ pasien TB Paru adalah laki-laki. Penderita TB Paru laki-laki maupun perempuan sama sama beresiko terjadinya putus berobat.

\section{Tidak Ada PMO}

Ada hubungan yang bermakna antara adanya PMO dengan putus berobat penderita TB Paru, dan penderita TB Paru yang tidak memiliki PMO berpeluang sebesar 3,778 kali beresiko terjadinya putus berobat dibanding dengan penderita yang memiliki PMO.

Menurut Depkes RI (2002), salah satu komponen DOTS (Directly Observed Treatment Short cousse) adalah pengobatan dengan paduan OAT jangka pendek dengan pengawasan langsung oleh PMO. Tugas seorang PMO bukanlah untuk menggantikan kewajiban pasien mengambil obat dari unit pelayanan kesehatan, tetapi tugas PMO yaitu: Mengawasi pasien TB agar menelan obat secara teratur sampai selesai pengobatan, memberi dorongan kepada pasien agar mau berobat teratur dan mengingatkan pasien untuk periksa ulang dahak pada waktu yang telah ditentukan.

Hasil penelitian yang dilakukan oleh Murtiwi (2009), didapat bahwa sebagian besar pasien yang tidak memiliki PMO yaitu sebanyak $69,9 \%$. Penelitian ini sejalan dengan penelitian yang dilakukan Amelda dkk (2012) adanya peran PMO dengan perilaku pasien TB Paru diperoleh nilai $\mathrm{OR}=3.636$ yang berarti pasien TB Paru yang tidak memiliki PMO berisiko 3.636 kali untuk tidak teratur berobat dibandingkan dengan penderita TB Paru yang memiliki PMO.

Penderita TB Paru yang tidak memiliki PMO lebih beresiko untuk mengalami putus berobat dibandingkan dengan penderita yang memiliki PMO dikarenakan tidak ada yang mengingatkan menelan obat, mengawasi dan memberikan dorongan dalam melakukan pengobatan secara tuntas.

\section{Kunjungan kePelayanan Kesehatan}

Ada hubungan yang bermakna antara kunjungan keyankes dengan putus berobat penderita Tb Paru, dan penderita TB Paru yang berkunjung keyankes dengan rujukan UPK berpeluang sebesar 6,057 kali beresiko terjadinya putus berobat dibanding dengan penderita yang berkunjung keyankes dengan inisiatif sendiri.
Menurut Depkes RI (2009) pelayanan kesehatan adalah setiap upaya yang diselenggarakan sendiri atau secara bersama-sama dalam suatu organisasi untuk memelihara dan meningkatkan kesehatan, mencegah dan menyembuhkan penyakit serta memulihkan kesehatan perorangan, keluarga, kelompok dan atupun masyarakat. Kunjungan kepelayanan kesehatan ada dua yaitu berkunjung atas inisiatif sendiri dan dari rujukan Unit Pelayanan Kesehatan (UPK). Berkaitan dengan hasil analisis yang dilakukan Jaka Prasetya (2012) yang dilakukan di wilayah Puskesmas Genuk Semarang, bahwa motivasi klien TB paru dipengaruhi oleh dua hal yaitu dari dalam diri pendirita (berkunjung kepelayanan kesehatan dengan inisiatif sendiri) dan motivasi dari luar (berkunjung atas rujukan dan dukungan dari keluarga maupun masyarakat). Kunjungan kepelayanan atas inisiatif sendiri merupakan modal dasar yang penting bagi seorang penderita TB paru dalam menentukan perilaku sehatnya selama masa pengobatan berlangsung.

\section{KESIMPULAN}

Faktor yang berhubungan dengan putus berobat pada penderita TB Paru di wilayah kerja Puskesmas Harapan Raya adalah umur, tidak ada PMO, dan kunjungan keyankes. Faktor yang tidak berhubungan dengan putus berobat pada penderita TB Paru di wilayah Kerja Puskesmas Harapan raya adalah jenis kelamin.

\section{SARAN}

Petugas kesehatan Puskesmas khususnya yang menangangi pengobatan TB Paru lebih menekankan bagi penderita TB Paru yang berusia produktif agar melakukan pengobatan hingga tuntas, menekankan untuk memiliki PMO agar dalam masa pengobatannya ada yang mengawasi dan mengingatkan, dan memberi dorongan agar motivasi dari diri sendiri lebih besar sehingga dalam berkunjung kepelayanan kesehatan atas dorongan dan inisiatif sendiri.sehingga dapat membantu penderita dalam melakukan pengobatnnya hingga tuntas.

\section{DAFTAR PUSTAKA}

Amelda, L Dkk. (2012). Hubungan Antara Pekerjaan, Pmo, Pelayanan Kesehatan, Dukungan Keluarga Dan Diskriminasi 
Dengan Perilaku Berobat Pasien Tb Paru. Makassar : Universitas Hasanuddin

Departemen Kesehatan, RI. (2008). Pedoman Nasional Penanggulangan Tuberkulosis: Jakarta

Dinas Kesehatan Provinsi Riau. (2011). Profil Kesehatan Provinsi Riau : Riau

Erawatyningsing, dkk. (2009). Faktor-Faktor Yang Mempengaruhi Ketidakpatuhan Berobat Pada Penderita Tuberkulosis Paru. Yogjakarta: Universitas Gajah Mada

Murtiwi. (2009). Keberadaan Pengawas Minum Obat (PMO) Pasien Tuberkulosis Paru Di Indonesia. Indonesia
Prasetyo, Jaka. (2012). Hubungan Motivasi Pasien Tb Paru Dengan Kepatuhan Dalam Mengikuti Program Pengobatan Sistem DOTS. Semarang: Fakultas Kesehatan UDINUS

Priska, Kondoy Dkk. (2012). Faktor-Faktor Yang Berhubungan dengan Kepatuhan Berobat Pasien Tuberkulosis Paru di Lima Puskesmas. Manado

Widayati, Nanik dan Ulfania, Nurul. (2013). Studi Deskriptif Faktor-faktor Penyebab Default Pada Penderita TB Paru Program Directly Observed Treadment ShortCourse (DOTS) Di RSUD Batang. Muhamadiyah: Muhamadiyah Pengkajangan 